\begin{tabular}{lllllll} 
O P E R A T I O N S R E S E A R C H A N D D E C I S I O N S \\
\hline No. 3
\end{tabular}

DOI: $10.37190 /$ ord210306

\title{
AN INVENTORY MODEL FOR DETERIORATING ITEMS WITH IMPERFECT QUALITY UNDER ADVANCE PAYMENT POLICY
}

\author{
BIMAN KANTI NATH, NABENDU SEN ${ }^{*}$ \\ Department of Mathematics, Assam University, Silchar, Assam 788011, India
}

\begin{abstract}
In the business world, it is generally observed that the supplier gives a cash discount due to advance payment. The buyer may either pay off the total purchase cost or a fraction of the total purchase cost before receiving the products. If the buyer makes full payment then he receives a cash discount instantly. If the buyer pays a fraction of the total purchase cost, then (s)he receives the cash discount while paying the remaining amount at the time of receiving the lot. Moreover, in most of the inventory models, it is generally assumed that the delivered lot contains only perfect items. But in reality, the presence of imperfect items in the received lot cannot be overlooked as it will affect the total profit of the system. Thus, the study of inventory models considering the presence of imperfect items in the lot makes the model more realistic and it has received much attention from inventory managers. This paper develops a model that jointly considers imperfect quality items and the concept of an advance payment scheme (full and partial). The objective is to determine optimal ordering quantity to maximise the total profit of the system. The necessary theoretical results showing the existence of global maximum is derived. The model is illustrated with the help of numerical examples, and sensitivity analysis is carried out on some important system parameters to see the effects on the total profit of the system. The study shows that a full advance payment scheme is beneficial for the buyer.
\end{abstract}

Keywords: advance payment, imperfect items, screening rate, deterioration, discount, price-dependent demand

\section{Introduction}

Inventory management is a part of supply chain management aiming to have the right goods at the right price at the right time to maintain the desired service level. It is one of the essential and challenging activities that any business organisation confronts. To keep a large pile of goods in stock for a longer time is usually not profitable due to

*Corresponding author, email address: nsen08@yahoo.com Received 18 February 2021, accepted 13 July 2021 
high holding costs and deterioration. And also, keeping low inventory may cause to stock out of the items due to high customers' demand. Thus, to be on the top of the market, every business organisation needs a perfect ordering policy to run the business smoothly from an economical point of view. Several factors influence the order quantity of an inventory system. Time of payment is one of such factors that greatly influence any inventory system. In the classical inventory model developed by Harris [14], it is assumed that the purchase cost is to be paid at the time of delivery of the items. In this direction, a lot of models have been developed [32, 46, 56, 47, 54, 64, and references therein]. However, this phenomenon is not always observed in the real market scenario. In the competitive dynamic market, it has become a challenging task for any business establishment or supplier to catch the attention of the customers and to turn potential customers into actual buyers. Thus, to stimulate sales, suppliers undertake different marketing strategies from time to time due to changing conditions of the market. Nowadays, the concept of post-payment or prepayment is widely practised by the majority of business organisations for easy product disposal and boasting up demand. In the case of post-payment, the supplier allows a certain period for settling the account after the receipt of items by the buyer. On the other hand, an advance payment policy is one where the supplier asks the buyer to pay all or a fraction of the purchasing cost. One of the benefits of advance payment from the buyer perspective is that it lowers the risk of cancellation of the order by the supplier. Moreover, in some cases, the buyer gets various prepayment facilities as quantity discount, cash discount, credit period extensions etc., from the supplier. This policy is also beneficial for suppliers because it does not stop the cash flow. Thus, this advance payment policy is most commonly used by suppliers in this modern era of a highly competitive market. In this study, we consider the advance payment policy and cash discount facility offered by suppliers due to advance payment.

In inventory literature, lots of models have been developed with delays in payments. For ready reference, one may refer to Das et al. [10], Shaikh et al. [52], Shaikh et al. [55] and literature cited therein. But only a few numbers of problems have been studied with prepayment policy. The concept of prepayment (advance payment) was introduced by Zhang [65] where the author obtained an optimal advance payment scheme with fixed prepayment cost. Maiti et al. [33] study an inventory model with stochastic lead time and price dependent demand over a finite time horizon under advance payment. They observe that advance payment has a positive effect on the inventory system. Gupta [13] extends this model, considering all inventory cost parameters as interval numbers and using a genetic algorithm (GA) to solve the problem. Thangam [62] develops an EOQ model for perishable items under two-echelon trade credit and advance payment. Taleizadeh et al. [60] offer an EOQ model for non-deteriorating items incorporating multiple partial prepayment schemes with constant demand under three conditions: no shortage, partial backlogging, and complete back-logging. This work is further extended 
in [59] for deteriorating items. Zhang et al. [66] study inventory policies under full advance payment, partial advance, and partially delayed payment conditions. Zia and Taleizadeh [68] propose an EOQ model with partial advance and partially delayed payment linked to ordering quantity under complete backlogging. Zhang et al. [67] suggest a two-stage supply chain model under an advance payment scheme. Tavakoli and Taleizadeh [61] also study an EOQ model for decaying items with full advance payment and conditional discount under no shortage, partial backlogging, and complete backlogging. Khan et al. [23] develop a two-warehouse inventory model for price-dependent demand under multiple advance payment and partial backlogging. This work is extended by Shaikh et al. [53], considering all inventory cost parameters as interval numbers. They use the particle swarm optimisation technique to solve the model. Khan et al. [24] offer a model with price and stock-dependent demand for deteriorating items under full and partial advance payment with a discount facility. Khan et al. [20] also discuss a lot size model for deteriorating items with price-dependent demand and order size-dependent discount policy. Khan et al. [22] examine the effect of advance payment for non-instantaneous deteriorating items in a two-warehouse inventory system under partial backlogging. Li et al. [31] build a model where the buyer uses an advance-cash-credit payment scheme to determine the optimal selling price. Krommyda et al. [28] resort to a general EOQ model with an advance-cash payment scheme where market tolerance permits backorders to occur at no extra costs for a fixed time. Chaudhari et al. [8] develop an inventory model for deteriorating items with quadratic demand with multiple advance payments. Agrawal et al. [1] consider partial trade credit and partial advance payment policy in their inventory model with a price discount on advance payment. Mashud et al. [36] develop a two-warehouse inventory model under multiple advance payment and trade credit policies with instalment dependent discount rates. Rahman et al. [44] feature an inventory model for perishable goods with hybrid price (a convex combination of linear and nonlinear price) and stock dependent demand under advance payment policy. Khan et al. [26] demonstrate an inventory model for perishable items with price and advertisement-dependent demand under an advance payment policy. Recently, Khan et al. [25] present a two-warehouse EOQ model linked to order hybrid advance payment and delayed in the payment scheme.

In the classical EOQ models, it is generally assumed that the arrived lot contains items of perfect quality. But, this assumption does not always hold. Inventory received may contain imperfect items as well. This may be due to imperfect production or destruction in shipment. The presence of imperfect quality items in the lot, if neglected, can lead to errors in determining optimal ordering size, cycle length, and associated inventory parameters. The presence of imperfect items in the lot not only affects the profit of the system, but their inadvertent supply to customers may cause loss of seller's goodwill. Thus, to maintain the supply of good items, the received lot needs to undergo a screening process as soon as the items enter the system for isolating them from the lot. The assumption regarding imperfect quality is very much realistic while studying lot- 
sizing models. Keeping this in mind, a great number of research works have been done in developing $\mathrm{EOQ} / \mathrm{EPQ}$ models for imperfect quality items.

Karlin [19] is probably the first to develop three single-stage newsvendor models considering the existence of imperfect quality items to characterise the optimal ordering policy. Porteus [42] elaborates on a significant relationship between the fraction of defective items and lot size. Rosenblatt and Lee [45] propose a production model where they show that the presence of imperfect items causes smaller production lot sizes. Cheng [9] suggest a model considering imperfect quality items with demand dependent on production cost. Ben-Daya and Hariga [4] study a lot-sizing policy with imperfect production. Salameh and Jaber [48] extend the EOQ model where the incoming lot contains a fraction of defective items (following a known probability distribution). The main highlight of the paper is that the defective items are sold at a reduced price after the end of the screening process. Their result shows that an increase in defective items increases the lot size which contradicts the findings of Rosenblatt and Lee [45] of reducing lot with the increase in imperfect items. Cárdenas-Barrón [7] corrects Salameh and Jaber [48] without violating their main idea. Goyal and Cárdenas-Barrón [11] propose an easy approach to determine lot size in the model by Salameh and Jaber [48]. Balkhi [3], Hou and Lin [16], Mondal et al. [38], Papachristos and Konstantaras [41] are some worth mentioning works in this regard. One may also refer to Khan et al. [21] for a comprehensive review on imperfect quality items up to the year 2011. MoussawiHaidar [39] examine the effect of deterioration on optimal ordering policy with constant demand in the presence of imperfect quality items in the received lot. Shaikh and Mishra [51] develop a model for deteriorating items with price and quadratic time-dependent demand, inflation, and preservation technology investment to determine optimal ordering policy where the received lot contains a fraction of defective items. Mandal and Giri [34] propose a two warehouse model with an imperfect production process of a vendor. They scrutinise the model under quantity discount and stock-dependent demand. Recently, Manna et al. [35] considers an imperfect production inventory model with inspection and selling price discount and warranty period-dependent demand. A very few works related to an imperfect lot under credit period policy are reported in inventory literature. We mention some of the works related to imperfect production and credit policy. Kumar et al. [29] study an EOQ model with a constant demand for the imperfect lot under a two-level credit policy. Sarkar [50] feature an inventory model that allows a delay in payment where the lot contains imperfect items. Ouyang et al. [40] give EOQ model in the presence of imperfect quality items under partial delay in payment linked to order quantity with constant demand. Sulak et al. [58] also propose an EOQ model with imperfect quality items under permissible delay in payment and completely backlogged shortages. Jaggi et al. [17] offer a two warehouse inventory model with an imperfect lot under permissible delay in payment. They consider constant demand and the 
fraction of defective items is a random variable following known probability distribution. Recently, Khanna et al. [27] build up an inventory model with imperfect quality items and inspection errors under a two-level trade credit policy.

Customers' demand is one of the important components in the inventory models. It is influenced by many factors as time, advertisement cost, stock of items, service level, quality, credit availability, price, etc. The most prominent out of them is the price of an item. It is seen that almost all the items are price sensitive. The law of demand based on economics and marketing theory states that lower priced items attract more customers and higher selling price has a negative effect, that is, demand increases with the decrease in selling price, and demand decreases when selling price increases. It is a single dominant factor regarding selection for purchasing an item by the customers. There are three basic ways to represent such behaviour of price-dependent demand curve: (i) linear function of selling price, $D(p)=a-b p$, where $a, b>0$, (ii) isoelastic price-dependent demand $D(p)=a p^{-b}$, where $a>0$ and $b>1$, (iii) exponential function of price such as $D(p)=a \mathrm{e}^{-b p}$, where $a, b>0$. All of these demand patterns follow the general assumption that $D(p)>0$, $\frac{d}{d p} D(p)<0$, and $\frac{\partial^{2}}{\partial p^{2}} D(p) \geq 0$ [31]. In this model, we consider the linear form of the demand function $D(p)=a-b p$, where $a, b>0$. There are many works whose authors take price-dependent demand, some of which are mentioned below.

Maiti et al. [33] derive an inventory model with price-dependent demand. Sridevi et al. [57] study an inventory model for deteriorating items with the Weibull rate of replenishment and price-dependent demand. Sana [49] discuss an EOQ model for perishable items with price-sensitive demand. He and Huang [15] develop an inventory model with price-dependent demand under preservation technology investment. Bhunia and Shaikh [5] also propose an inventory model with Weibull distributed deterioration and price-sensitive demand. Alfares and Ghaithan [2], Jaggi et al. [17], Khan et al. [23], Mishra et al. [37], Tiwary et al. [63] etc. are some notable works related to price-sensitive demand. One may also refer to Rahman et al. [43], Li et al. [31] and literature cited therein for inventory models with price-dependent demand.

From the above survey, it is seen that lots of models have been developed under advance payment policy for deteriorating items. Several models have also been made in the presence of imperfect quality items with or without permissible delay in payment. But, as far as our survey is concerned, till now no one has studied the effect of advance payment on ordering policy for an imperfect lot under a deteriorating condition with price-dependent demand. Thus, in this study, an attempt is made to fill up this gap. In this paper, an EOQ model that embodies the following features is proposed:

- Advance payment (full advance payment and partial advance payment) policy is adopted and a cash discount facility due to advance payment is rendered by the supplier to the buyer. 
- The presence of imperfect quality items in the lot is considered. The imperfect items are sold in a single batch at a reduced price as soon as the screening process is over.

- Demand is price-dependent.

Table 1. Comparison of some related research works and the present model

\begin{tabular}{|c|c|c|c|c|c|c|}
\hline Reference & $\begin{array}{c}\text { Imperfect } \\
\text { quality } \\
\text { items }\end{array}$ & Payment & $\mid \begin{array}{c}\text { Cash } \\
\text { discount }\end{array}$ & Demand & Deterioration & Shortages \\
\hline$[18]$ & yes & $\begin{array}{l}\text { delay } \\
\text { in payment }\end{array}$ & no & constant & \multirow{2}{*}{ constant } & no \\
\hline$[23]$ & \multirow{5}{*}{ no } & $\begin{array}{l}\text { multiple } \\
\text { prepayment }\end{array}$ & no & $\begin{array}{l}\text { price- } \\
\text {-dependent }\end{array}$ & & partial backlogging \\
\hline$[22]$ & & $\begin{array}{l}\text { multiple } \\
\text { prepayment }\end{array}$ & no & $\begin{array}{l}\text { price- } \\
\text {-dependent }\end{array}$ & $\begin{array}{l}\text { constant } \\
\text { (non- } \\
\text {-instantaneous) }\end{array}$ & partial backlogging \\
\hline$[24]$ & & \begin{tabular}{|l|} 
full and partial \\
advance payment
\end{tabular} & yes & $\begin{array}{l}\text { price- and stock- } \\
\text {-dependent }\end{array}$ & constant & partial backlogging \\
\hline$[30]$ & & \begin{tabular}{|l|} 
partial advance \\
partial delayed \\
payment
\end{tabular} & no & constant & \multirow[t]{2}{*}{ no } & $\begin{array}{l}\text { no backlogging, } \\
\text { partial backlogging, } \\
\text { complete backlogging }\end{array}$ \\
\hline$[33]$ & & $\begin{array}{l}\text { advance } \\
\text { payment }\end{array}$ & no & $\begin{array}{l}\text { price- } \\
\text {-dependent }\end{array}$ & & complete backlogging \\
\hline [39] & \multirow{2}{*}{ yes } & no & no & constant & \multirow{3}{*}{ constant } & $\begin{array}{l}\text { no backlogging, } \\
\text { partial backlogging }\end{array}$ \\
\hline$[51]$ & & no & no & $\begin{array}{l}\text { price- and time- } \\
\text {-dependent }\end{array}$ & & no \\
\hline$[59]$ & \multirow{3}{*}{ no } & $\begin{array}{l}\text { multiple } \\
\text { prepayment }\end{array}$ & no & constant & & $\begin{array}{l}\text { no backlogging, } \\
\text { complete backlogging }\end{array}$ \\
\hline$[60]$ & & $\begin{array}{l}\text { multiple } \\
\text { prepayment }\end{array}$ & no & constant & \multirow{2}{*}{ no } & $\begin{array}{l}\text { no backlogging, } \\
\text { partial backlogging, } \\
\text { complete backlogging }\end{array}$ \\
\hline$[66]$ & & $\begin{array}{l}\text { full advance } \\
\text { partial advance } \\
\text { partial delayed }\end{array}$ & yes & constant & & no \\
\hline This paper & yes & $\begin{array}{l}\text { full and partial } \\
\text { advance }\end{array}$ & yes & $\begin{array}{l}\text { price } \\
\text {-dependent }\end{array}$ & constant & no \\
\hline
\end{tabular}

The objective of the present study is to determine an optimal ordering policy to maximise the total profit per time unit. The model may be useful for retailers, wholesalers, shopping malls, etc. because this will help in taking important replenishment decisions. Table 1 presents a comparison of some related research works and the present model. 
The rest of the paper is organised as follows: In Section 2, the model description is presented. In Section 3, assumptions and notations used throughout this paper are provided. In Section 4, mathematical models under both full advance and partial advance payment schemes are formulated, and the corresponding total average profit functions are derived. In Section 5, some special cases are described. In Section 6, numerical examples are taken to illustrate the models. In Section 7, sensitivity analysis is carried out to study the effects of changes in different parameters of the system. In Section 8, some managerial implications are made. Finally, in Section 9, a conclusion is drawn and future research direction is indicated.

\section{Definition of the problem}

Consider a situation where a buyer places an order and to confirm it, the buyer pays all or a fraction of the total purchasing cost at the time of order. The supplier also offers a cash discount for early payment by the buyer. The cash discount on purchase cost is rendered by the supplier to attract its customers. These situations are beneficial for both the supplier and the buyer. From the buyer's perspective, (s)he gets cash discount that reduces its purchase cost and from a supplier point of view, apart from attracting their potential customers, it maintains the cashflow. It is clear that to avail the opportunity of cash discount on prepayment, the buyer should have a sufficient cash balance. But for the retailer (buyer), who runs a small business organisation, pays the prepayment amount by borrowing money from a bank or a third party at a specific interest rate. This payable amount will serve as capital for the buyer. The cost of interest for borrowing money from the bank or other sources is an additional cost along with the capital. As based on the amount of prepayment, two cases may arise - full advance payment, and partial advance payment. In case of full advance payment, the buyer gets an instant cash discount on purchase cost with a certain discount rate. But, sometimes the buyer faces problems paying the whole purchasing amount. Instead, (s)he pays a certain fraction to meet the supplier criteria of the advance payment and pays the remaining amount at the time of receiving the goods. In case of partial advance payment, the supplier does not offer any discount instantly but to keep the customer in hand the supplier offers a cash discount at the time of delivery of the goods with a discount rate that is less than that in the full advance payment case. The buyer pays off the remaining amount after deducting the discounted amount. Moreover, the implicit assumption of all perfect items in the received lot does not always hold in practice. The chance of imperfect quality items in the lot, however, cannot be overlooked in developing a realistic model. This present study identifies the buyer's inventory model for deteriorating items with imperfect quality and price-dependent demand. The model is developed under both cases, namely full advance payment and partial advance payment schemes. 


\section{Assumptions and notations}

\subsection{Assumptions}

- The model deals with a single deteriorating item.

- Demand is selling price-dependent. It is evident that the higher the price, the lower the demand is, and vice versa. It is a linear decreasing function of the selling price of the form $D(p)=a-b p>0$, where $a, b>0$ [23].

- Planning horizon is infinite.

- Replenishment rate is infinite and lead time is $L$.

- Following Moussawi-Haidar et al. [39], it is assumed that there is no repair or replacement of the deteriorating items for the period under consideration. The received lot contains a certain fraction of imperfect items. This is due to the faulty production process, low labour skills or improper transport. Thus, the lot needs screening to isolate them to supply good items to the customers. Here, the screening process and demand proceed simultaneously. The screening rate $\left(s_{r}\right)$ is assumed to be greater than the demand rate $(D)$, so that demand can be met, along with the screening process running in parallel, from the perfect items [17].

- After the screening process is over, the imperfect items are sold out immediately at a reduced price in a single batch [17].

- Shortages are not allowed.

- As discussed in Section 2 (problem description), an advance payment scheme is adopted by the buyer (retailer). In the case of full advance payment, a discount rate $d_{1}$ on the total purchase cost is given by the supplier. In the case of partial advance payment, the buyer pays a fraction $\delta(0<\delta<1)$ of the total purchasing cost at the time of placing the order. The remaining payment is made by the buyer at the time of receiving the lot after deducting the discounted amount with the discount rate $d_{2}\left(<d_{1}\right)$ applied on the total purchase cost [24].

\subsection{Notations}

\section{Symbols}

$D(p)$ - demand rate

$Q \quad$ - quantity to be ordered

$I(t) \quad-$ inventory level at any time $t$

$\theta \quad-$ deterioration rate, $0<\theta<1$ 
$A \quad-$ ordering cost per order in rupees

$x \quad-$ per unit purchasing cost of the item in rupees, $p>x$

$h \quad-$ holding cost per unit time per item in rupees

$m \quad$ - fraction of imperfect items in the lot $Q$

$c \quad-$ per unit selling price of the imperfect items in rupees, $c<x$

$s_{c} \quad-$ screening cost per item in rupees

$s_{r} \quad-$ screening rate per unit per year

$t_{s} \quad-\quad$ time in years at which screening process ends

$L \quad-$ lead time in years

$I_{e} \quad-$ loan interest rate per rupees per year

$d_{1} \quad-$ discount rate (\%) in case of full advance payment

$d_{2} \quad-$ discount rate (\%) in case of partial advance payment

$T C_{1} \quad-$ total cost in rupees under full advance payment

$T C_{2} \quad$ - total cost in rupees under partial advance payment

$T P U_{1}$ - total profit per unit time in rupees under full advance payment

$T P U_{2}-$ total profit per unit time in rupees under partial advance payment

\section{Decision variables}

$Q \quad$ - independent decision variables

$T P U_{i}-$ dependent decision variables, $i=1,2$

\section{Formulation of the mathematical model}

As based on the choice of the buyer, we have two cases: (i) full advance payment, and (ii) partial advance payment.

\subsection{Full advance payment}

Let us consider that the buyer (retailer) places an order of $Q$ units of a product by paying the full purchasing amount at the time of placing the order. The buyer receives an instant cash discount at the rate $d_{1}$ due to advance payment. That is, the amount paid to the supplier at the time of placing the order is $x Q-d_{1} x Q=\left(1-d_{1}\right) x Q$. The buyer receives the good after a period $L$. Let the received lot contain $m Q$ units of imperfect 
items. The deterioration starts to play its role as soon as the lot enters the system. The screening process starts as soon as the lot is received and ends up at the time $t=t_{s}=Q / s_{r}$. The imperfect items detected are kept in the store and sold out at the end of the screening period at the reduced price $c$ per unit in a single lot. The inventory level depletes due to demand and deterioration and drops to zero at $t=T$. The description of the model is depicted in Fig. 1.

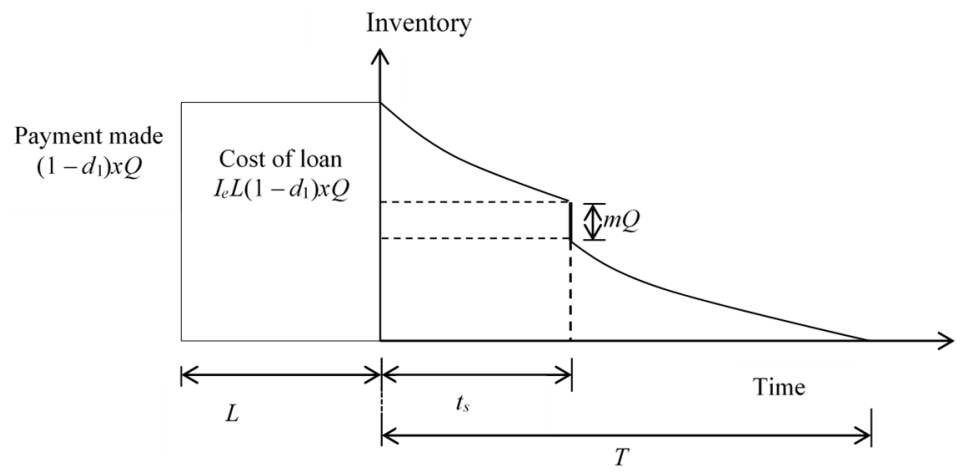

Fig. 1. Graphical representation of inventory level under full advance payment

The differential equation along with the boundary conditions representing the described situation is as follows:

$$
\begin{gathered}
\frac{d}{d t} I(t)+\theta I(t)=-(a-b p), 0 \leq t \leq T \\
I(0)=Q, I\left(t_{s}^{+}\right)=I\left(t_{s}\right)-m Q \text { and } I(T)=0
\end{gathered}
$$

The solutions of the differential equation (1) with the boundary conditions (2) are as below:

$$
\begin{gathered}
I(t)=-\frac{a-b p}{\theta}+\left(Q+\frac{a-b p}{\theta}\right) \mathrm{e}^{-\theta t}, 0 \leq t \leq t_{s} \\
I(t)=-\frac{a-b p}{\theta}+\left(Q+\frac{a-b p}{\theta}-m Q e^{\theta t_{s}}\right) \mathrm{e}^{-\theta t}, t_{s}<t \leq T
\end{gathered}
$$

Since $I(T)=0$, we get the value of $T$ from the equation: 


$$
T=\frac{1}{\theta} \log \left|1+\frac{Q \theta}{a-b p}\left(1-m \mathrm{e}^{\theta t_{s}}\right)\right|
$$

Let $N_{0}(Q, m)$ and $w_{0}$ be the total number of good items and deteriorated items, respectively. Then, by applying an argument similar to Jaggi et al. [17], it is easy to obtain $N_{0}(Q, m)=Q-m Q-w_{0}$ and $w_{0}=Q-m Q-(a-b p) T$. So, $N_{0}=(a-b p) T$. To sustain the smooth supply of customers' demand, it is assumed that the number of good items $N_{0}$ is greater than or equal to the demand during screening. That is, we have $N_{0} \geq(a-b p) t_{s}$. This on simplification gives

$$
T \geq t_{s}>0
$$

On simplifying inequality (6), we get the following condition on the portion of defective items in the lot:

$$
m \leq-\frac{a-b p}{Q \theta}+\left(1+\mathrm{e}^{-\theta t_{s}}\right) \mathrm{e}^{-\theta t s}
$$

Now, we calculate different associated costs. The total cost of the system consists of the following elements:

$A \quad$ - ordering cost per order

$P C$ - purchase cost

$C O L-$ cost of loan

$H C$ - holding cost

$S C$ - screening cost where:

$$
\begin{gathered}
P C=\left(1-d_{1}\right) x Q \\
C O L=I_{e} L\left(1-d_{1}\right) x Q \\
H C=h \int_{0}^{t_{s}} I(t) d t+h \int_{t_{s}}^{T} I(t) d t=h\left(-\frac{a-b p}{\theta} T+\frac{1}{\theta} Q(1-m)\right) \\
S C=s_{c} Q
\end{gathered}
$$

Therefore, the total cost under full advance payment is 


$$
\begin{aligned}
T C_{1} & =A+P C+C O L+H C+S C \\
& =A+\left(1+I_{e} L\right)\left(1-d_{1}\right) x Q+h\left(-\frac{a-b p}{\theta} T+\frac{1}{\theta} Q(1-m)\right)+s_{c} Q
\end{aligned}
$$

The total sales revenue is $T S R=N_{0} p+c m Q=p(a-b p) T+c m Q$. Therefore, the total profit per unit time is

$$
\begin{aligned}
T P U_{1}(Q) & =T S R-T C_{1}=\frac{p(a-b p) T+c m Q-T C_{1}}{T} \\
& =\frac{(a-b p)\left(p+\frac{h}{\theta}\right) T+\left(c m-s_{c}-\left(1+I_{e} L\right)\left(1-d_{1}\right) x-\frac{h}{\theta}(1-m)\right) Q-A}{T}
\end{aligned}
$$

Now, we shall show that the total average profit function given by expression (8) possesses global maxima. For simplification, we let

$$
\begin{aligned}
& g(Q)=1+\frac{Q \theta}{a-b p}\left(1-m \mathrm{e}^{\theta t_{s}}\right) \\
& \Phi_{1}=(a-b p)\left(p+\frac{h}{\theta}\right) \\
& \Phi_{2}=c m-s_{c}-\left(1+I_{e} L\right)\left(1-d_{1}\right) x-\frac{h}{\theta}(1-m) \\
& M(Q)=\Phi_{2} \theta Q-A \theta \\
& N(Q)=\log |g(Q)| \\
& \Phi(x)=\Phi_{1}+x
\end{aligned}
$$

Therefore, the expression (8) can be written as

$$
T P U_{1}(Q)=\Phi_{1}+\frac{\Phi_{2} \theta Q-A \theta}{\log |g(Q)|}=\Phi_{1}+\frac{M(Q)}{N(Q)}=\Phi\left(\frac{M(Q)}{N(Q)}\right)
$$

Next, our aim is to show that $\operatorname{TPU}_{1}(Q)$ is pseudo concave. For this, let $\Phi_{2}<0$.

Clearly, $\Phi_{1}>0$ and $M(Q)=\Phi_{2} \theta Q-A \theta<0$ as $\Phi_{2}<0$. Also, from inequality (6), we see that $N(Q)=\theta T>0$.

Now, we shall show that $N(Q)$ is a concave function.

$$
\frac{d}{d Q} g(Q)=\frac{\theta}{a-b p}\left(1-m \frac{Q \theta \mathrm{e}^{\theta t_{s}}}{s_{r}}-m \mathrm{e}^{\theta t_{s}}\right)
$$




$$
\frac{d^{2}}{d Q^{2}} g(Q)=\frac{\theta}{a-b p}\left(-\frac{m \theta}{s_{r}}\left(\frac{Q \theta \mathrm{e}^{\theta t_{s}}}{s_{r}}+\mathrm{e}^{\theta t_{s}}\right)-\frac{m \theta}{s_{r}} \mathrm{e}^{\theta t_{s}}\right)<0
$$

Therefore,

$$
\frac{d}{d Q} N=\frac{\frac{d}{d Q} g(Q)}{g(Q)}
$$

and

$$
\frac{d^{2}}{d Q^{2}} N=\frac{g(Q) \frac{d^{2}}{d Q^{2}} g(Q)-\left(\frac{d}{d Q} g(Q)\right)^{2}}{(g(Q))^{2}}<0
$$

This shows that $N(Q)$ is concave on $(0, \infty)$. Also, $M(Q)$ being a one-dimensional affine function is concave on $(0, \infty)$. Thus, $\frac{M(Q)}{N(Q)}$ is a ratio of two concave functions, where $M(Q)$ is non-positive and $N(Q)$ is positive function. Moreover, $M(Q)$ and $N(Q)$ are differentiable functions.

Therefore, the ratio $\frac{M(Q)}{N(Q)}$ is a pseudo-concave [6, p. 245]. Again, the function $\Phi(x)=\Phi_{1}+x$ is differentiable such that $\frac{d}{d x} \Phi(x)=\Phi_{1}>0$. Therefore, the function $\Phi\left(\frac{M(Q)}{N(Q)}\right)=\Phi_{1}+\frac{M(Q)}{N(Q)}=T P U_{1}(Q)$ is pseudo-concave [6, p. 243]. The next result shows the optimality of the total average profit function under case 1 .

Result 1. If $\Phi_{2}<0$, then a local maximum of $T P U_{1}(Q)$, if exists, is the unique global maximum on $(0, \infty)$.

Proof. From the above discussion we see that $T P U_{1}(Q)$ is pseudo-concave. Thus, any local maximum is a global maximum. It only remains to show that $\operatorname{TPU}_{1}(Q)$ has unique local maxima. Now, on putting $\frac{d T P U_{1}}{d Q}=0$ and simplifying, we get 


$$
f(Q)=N g(Q) \Phi_{2} \theta-M \frac{d}{d Q} g(Q)=0
$$

This implies that $f^{\prime}(Q)=-M \frac{d^{2}}{d Q^{2}} N<0$. Therefore, $f$ is strictly decreasing function of $Q$. Moreover, $f(0)=\frac{A \theta^{2}(1-m)}{a-b p}>0$. Therefore, the root of $f(Q)=0$, if exists is unique and $Q \in(0, \infty)$. Now, $\frac{d T P U_{1}}{d Q}=0 \Leftrightarrow f(Q)=0$. Thus if $Q$ is any local maximum then it is unique. Hence we are done.

\subsection{Partial advance payment}

In this case, the buyer cannot pay the whole purchasing amount. He pays a fraction $\delta(0<\delta<1)$ of the total purchase cost at the time of placing the order. That is, the retailer pays $\delta x Q$ at the time of ordering. At the time of receiving the goods, the buyer gets the cash discount at the rate $d_{2}\left(<d_{1}\right)$ so that the buyer pays the remaining payment amount $(1-\delta) x Q-d_{2} x Q$ to the supplier. Therefore, the purchase cost and cost of the loan, in this case, are $P C=\delta x Q+(1-\delta) x Q-d_{2} x Q=\left(1-d_{2}\right) x Q$ and $C O L=I_{e} L \delta x Q$, respectively. The description of the model after receiving the lot is the same as that in case I (see Fig. 2).

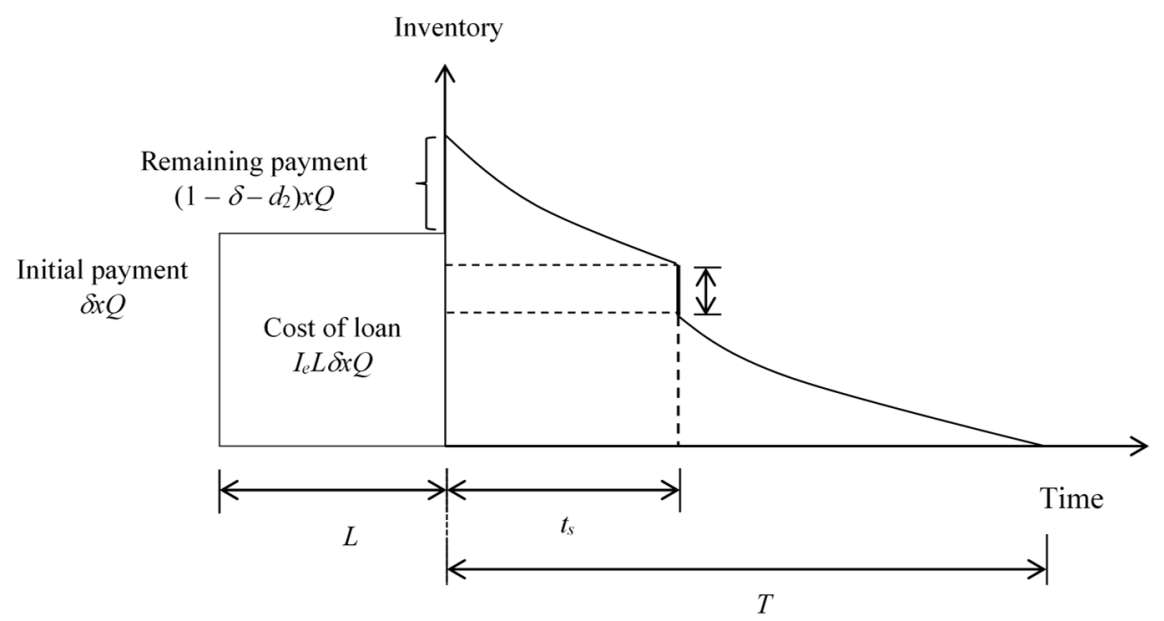

Fig. 2. Graphical representation of inventory level under partial advance payment 
Therefore, proceeding similarly to the case I, the total cost under partial advance payment is as below

$$
\begin{aligned}
T C_{2} & =A+P C+C O L+H C+S C \\
& =A+\left(1+\delta I_{e} L-d_{2}\right) x Q+h\left(-\frac{a-b p}{\theta} T+\frac{1}{\theta} Q(1-m)\right)+s_{c} Q
\end{aligned}
$$

The total profit per unit time is

$$
\begin{aligned}
T P U_{2}(Q) & =\frac{p(a-b p) T+c m Q-T C_{2}}{T} \\
& =\frac{(a-b p)\left(p+\frac{h}{\theta}\right) T+\left(c m-s_{c}-\left(1+\delta I_{e} L-d_{2}\right) x-\frac{h}{\theta}(1-m)\right) Q-A}{T}
\end{aligned}
$$

As in case I, we have a similar result of optimality for total profit function under case II.

Result 2. If $\Phi_{3}<0$, then a local maximum of $\operatorname{TPU}_{2}(Q)$, if exists, is the unique global maximum on $(0, \infty)$, where $\Phi_{3}=c m-s_{c}-\left(1+\delta I_{e} L-d_{2}\right) x-\frac{h}{\theta}(1-m)$

Proof. Similar to that of result 1.

\section{Some special cases}

\subsection{Model with imperfect items and without advance payment policy}

Setting $I_{e}=0, d_{1}=0$ in case of full advance payment and $I_{e}=0, d_{2}=0$ in case of partial advance payment, we get from expressions (8) and (9) the total profit per unit time as

$$
T P U=T P U_{1}=T P U_{2}=\frac{(a-b p)\left(p+\frac{h}{\theta}\right) T+\left(c m-s_{c}-x-\frac{h}{\theta}(1-m)\right) Q-A}{T}
$$

where

$$
T=\frac{1}{\theta} \log \left|1+\frac{Q \theta}{a-b p}\left(1-m e^{\theta t_{s}}\right)\right|
$$


5.2. Model without imperfect items and with full advance payment policy

Setting $m=0, s_{c}=0$, we get from expressions (8) the total profit per unit time as

$$
T P U_{1}(Q)=\frac{(a-b p)\left(p+\frac{h}{\theta}\right) T+\left(-\left(1+I_{e} L\right)\left(1-d_{1}\right) x-\frac{h}{\theta}\right) Q-A}{T}
$$

where

$$
T=\frac{1}{\theta} \log \left|1+\frac{Q \theta}{a-b p}\right|=\frac{1}{\theta} \log \left(1+\frac{Q \theta}{a-b p}\right)
$$

\subsection{Model without imperfect items and with partial advance payment policy}

Setting $m=0, s_{c}=0$, we get from expression (9) the total profit per unit time as

$$
T P U_{2}(Q)=\frac{(a-b p)\left(p+\frac{h}{\theta}\right) T+\left(-\left(1+\delta I_{e} L-d_{2}\right) x-\frac{h}{\theta}\right) Q-A}{T}
$$

where

$$
T=\frac{1}{\theta} \log \left|1+\frac{Q \theta}{a-b p}\right|=\frac{1}{\theta} \log \left(1+\frac{Q \theta}{a-b p}\right)
$$

5.4. Model without imperfect items and without advance payment policy

Setting $m=0, s_{c}=0$ in expression (10), we get the total profit per unit time:

$$
T P U=T P U_{1}=T P U_{2}=\frac{(a-b p)\left(p+\frac{h}{\theta}\right) T+\left(-x-\frac{h}{\theta}\right) Q-A}{T}
$$

where

$$
T=\frac{1}{\theta} \log \left|1+\frac{Q \theta}{a-b p}\right|=\frac{1}{\theta} \log \left(1+\frac{Q \theta}{a-b p}\right)
$$


Applying a similar argument used in the proof of result 1, it is easy to prove that local maxima of the total profit function given by the expressions (10)-(13), if exist, will be the unique global maxima.

\section{Numerical illustration}

The optimal values are obtained through the following steps:

\section{Algorithm}

Step 1. Set the parameters

Step 2. Solve $\frac{d\left(T P U_{i}\right)}{d Q}=0, i=1,2$.

Step 3. Test the second order condition $\frac{d^{2}\left(T P U_{i}\right)}{d Q^{2}}<0, i=1,2$.

Step 4. Find the optimal values $T^{*}, Q^{*}, T P U_{i}^{*}$.

To illustrate and validate the developed model, a hypothetical system with the values of different parameters have been presented in terms of the following examples.

Example 1. For full advance payment (Case 4.1)

$A=1000 /$ order; $I_{e}=$ Rs $0.3 /$ year; $L=0.025$ year; $d_{1}=20 \% ; x=$ Rs $45 /$ unit;

$h=$ Rs 5/year/unit; $\theta=0.1 ; m=0.05 ; c=$ Rs 30/unit;

$s_{c}=$ Rs 1/unit; $a=15000$ units/year; $b=1.5 ; p=$ Rs 70/unit; $s_{r}=60000$ units/year.

The optimal value of screening period, cycle length, ordering quantity and total profit per unit time are

$t_{s}^{*}=0.0315112$ year; $T=0.119845$ year;

$Q^{*}=1890.67 \approx 1891$ units; $T P U_{1}^{*}=$ Rs 427062.

For $Q=Q^{*}, \frac{d^{2}}{d Q^{2}} T P U_{1}=-0.00463108<0$. This means that $Q=Q^{*}$ is a local maximum. Hence, by result 1 , it is the unique global maximum. The concavity can be observed from Fig. 3.

Example 2. For partial advance payment (Case 4.2)

$A=1000 /$ order; $I_{e}=$ Rs $0.3 /$ year; $L=0.025$ year;

$d_{2}=10 \% ; \delta=0.6 ; x=$ Rs $45 /$ unit;

$h=$ Rs 5/year/unit; $\theta=0.1 ; m=0.05 ; c=$ Rs 30/unit;

$s_{c}=$ Rs 1/unit; $a=15000$ units/year;

$b=1.5 ; p=$ Rs 70/unit; $s_{r}=60000$ units/year. 


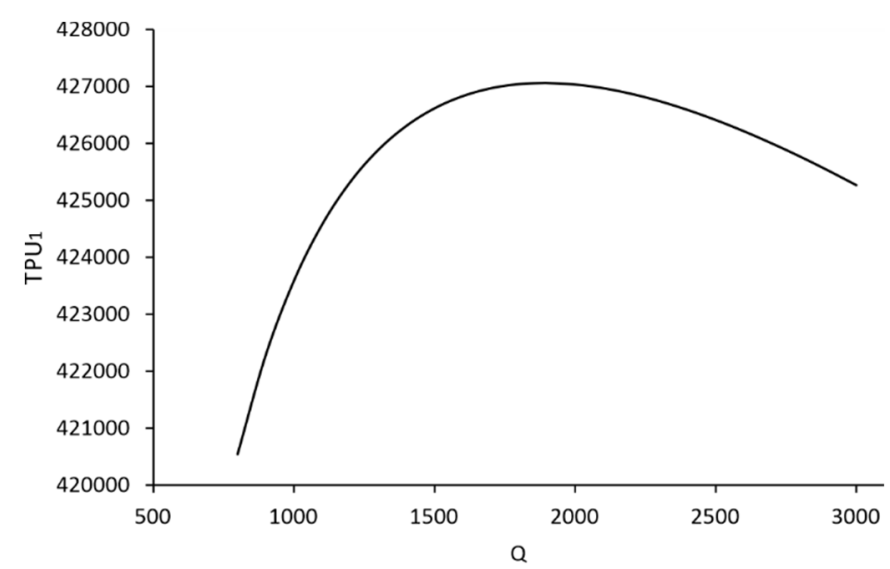

Fig. 3. Total profit per unit time vs. order quantity in the case of $100 \%$ advance payment (Case 4.1 )

The optimal value of screening period, cycle length, ordering quantity and total profit per unit time are

$$
\begin{aligned}
& t_{s}^{*}=0.0308294 \text { year; } T=0.117268 \text { year; } \\
& Q^{*}=1849.76 \approx 1850 \text { units } ; T P U_{2}^{*}=\operatorname{Rs} 366723 .
\end{aligned}
$$

Here also, for $Q=Q^{*}, \frac{d^{2}}{d Q^{2}} T P U_{2}=-0.00494535<0$. Hence, by result 2 , it is the unique global maximum. The concavity can be observed from Fig. 4.

Example 3. System with imperfect items and without advance payment policy (Case 5.1)

$A=1000 /$ order; $x=$ Rs 45/unit; $h=$ Rs 5/year/unit; $\theta=0.1 ; m=0.05 ; \mathrm{c}=$ Rs 30/unit; $s_{c}=$ Rs 1/unit; $a=15000$ units/year; $b=1.5 ; p=$ Rs 70/unit; $s_{r}=60000$ units/year.

The global optimal solution is

$$
\begin{aligned}
& t_{s}^{*}=0.0304111 \text { year; } T=0.115687 \text { year; } \\
& Q^{*}=1824.67 \approx 1825 \text { units } ; T P U^{*}=\operatorname{Rs} 327684 .
\end{aligned}
$$

Example 4. System without imperfect items and with full advance payment policy (Case 5.2)

$$
\begin{aligned}
& A=1000 / \text { order; } I_{e}=\text { Rs } 0.3 / \text { year; } L=0.025 \text { year; } d_{1}=20 \% ; x=\text { Rs } 45 / \text { unit; } \\
& h=\text { Rs 5/year/unit; } \theta=0.1 ; a=15000 \text { units/year; } b=1.5 ; p=\text { Rs 70/unit; }
\end{aligned}
$$

The global optimal solution is

$$
T=0.122534 \text { year; } Q^{*}=1836.38 \approx 1837 \text { units } ; T P U_{1}^{*}=\text { Rs } 449925 \text {. }
$$




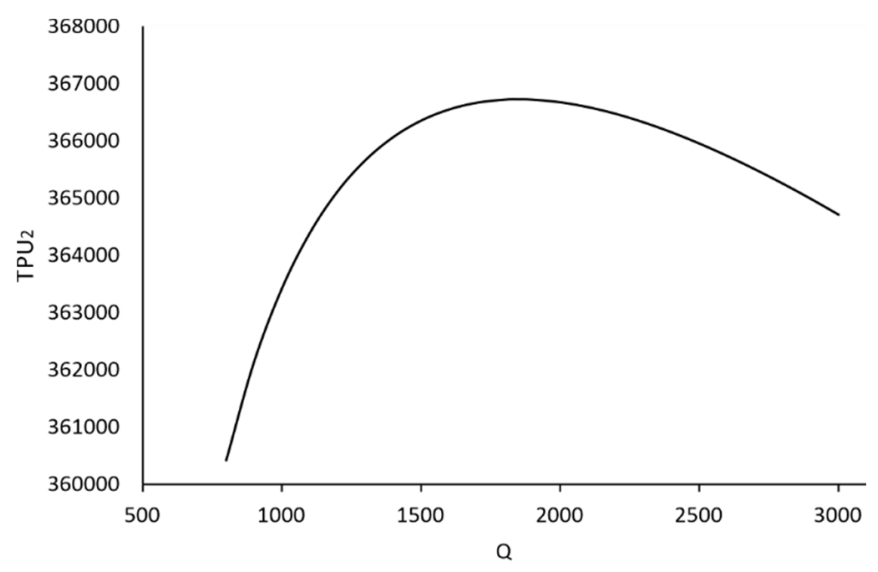

Fig. 4. Total profit per unit time vs. order quantity in the case of $60 \%$ advance payment (Case 4.2)

Example 5. Without imperfect items and with partial advance payment policy (Case 5.3)

$$
\begin{aligned}
& A=1000 / \text { order; } I_{e}=\text { Rs } 0.3 / \text { year; } L=0.025 \text { year; } \\
& d_{2}=10 \% ; \delta=0.6 ; x=\mathrm{Rs} 45 / \text { unit; } \\
& h=\text { Rs 5/year/unit; } \theta=0.1 ; \quad a=15000 \text { units/year; } b=1.5 ; p=\text { Rs 70/unit. }
\end{aligned}
$$

The global optimal solution is

$$
T=0.119985 \text { year; } Q^{*}=1797.94 \approx 1798 \text { units } ; T P U_{2}^{*}=\text { Rs } 392605 \text {. }
$$

Example 6. Without imperfect items and without advance payment policy (Case 5.4)

$A=1000 /$ order; $x=\mathrm{Rs} 45 /$ unit; $h=\mathrm{Rs}$ 5/year/unit; $\theta=0.1 ; a=15000$ units/ year; $b=1.5 ; p=$ Rs $70 /$ unit.

The global optimal solution is

$$
T=0.118418 \text { year; } Q^{*}=1774.32 \approx 1775 \text { units } ; T P U^{*}=\text { Rs } 355519 \text {. }
$$

The optimal values obtained for the different cases (examples 1-6), keeping similar numerical values of common parameters are presented in Table 2. The optimal values of total average profit in Cases 4.1 and 4.2 (Cases 5.2 and 5.3, respectively) are larger than that in Case 5.1 (Case 5.4, respectively). That is, the profit calculated in the case of an advance payment scheme (full or partial) is more than that without an advance payment scheme. It follows that the advance payment (full or partial) scheme has a positive effect on the total profit of the system. Moreover, comparing the optimal values of total average profit (Case 4.1 with 4.2 and Case 5.2 with 5.3), it is observed that full advance payment is more profitable. So, the buyer should go for a full advance payment policy to earn more profit. Further, an advance payment scheme encourages the buyer to purchase more items to increase the total profit of the system. Again, comparing the 
optimal values (Case 4.1 with 5.2, Case 4.2 with 5.3, and Case 5.1 with 5.4), it is observed that non-consideration of imperfect items in the lot leads to an overestimation of cycle length and total profit of the system whereas underestimation of ordering quantity.

Table 2. Optimal parameters obtained for the various cases

\begin{tabular}{|l|c|c|c|}
\hline \multicolumn{1}{|c|}{ Case } & $\begin{array}{c}\text { Cycle length } \\
T^{*}\end{array}$ & $\begin{array}{c}\text { Ordering quantity } \\
Q^{*}\end{array}$ & $\begin{array}{c}\text { Total profit } \\
\text { per unit time } \\
T P U^{*}\end{array}$ \\
\hline With full advance payment (Case 4.1) & 0.119845 & 1891 & 427062 \\
\hline With partial advance payment (Case 4.2) & 0.117268 & 1850 & 366723 \\
\hline $\begin{array}{l}\text { With imperfect items } \\
\text { and without advance payment policy (Case 5.1) }\end{array}$ & 0.115687 & 1825 & 327684 \\
\hline $\begin{array}{l}\text { Without imperfect items } \\
\text { and with full advance payment policy (Case 5.2) }\end{array}$ & 0.122534 & 1837 & 449925 \\
\hline $\begin{array}{l}\text { Without imperfect items } \\
\text { and with partial advance payment policy (Case 5.3) }\end{array}$ & 0.119985 & 1798 & 392260 \\
\hline $\begin{array}{l}\text { Without imperfect items } \\
\text { and without advance payment policy (Case 5.4) }\end{array}$ & 0.118418 & 1775 & 355519 \\
\hline
\end{tabular}

\section{Sensitivity analysis}

In this section, to investigate the effect of changes of inventory parameters on the optimal values, sensitivity analyses are performed with respect to example 1 . These analyses are carried out by changing one parameter by $\pm 10 \%$ and $\pm 20 \%$ at a time and keeping other parameters at their original values. The results of these analyses are shown in Table 3.

Table 3. Sensitivity table of the parameters on the optimal solution for Example 1

\begin{tabular}{|c|c|c|c|c|c|}
\hline \multirow{3}{*}{ Parameter } & \multirow{2}{*}{$\begin{array}{c}\text { Change } \\
{[\%]}\end{array}$} & \multirow{2}{*}{ Value } & \multicolumn{3}{|c|}{ Per cent change } \\
\cline { 3 - 6 } & & $T^{*}$ & $Q^{*}$ & $T P U^{*}$ \\
\hline \multirow{5}{*}{$a=1000$} & -20 & 800 & -10.5169 & -10.5751 & 0.4123 \\
\cline { 2 - 6 } & -10 & 900 & -5.1107 & -5.14103 & 0.2004 \\
\cline { 2 - 6 } & 10 & 1100 & 4.8596 & 4.8908 & -0.1908 \\
\cline { 2 - 6 } & 20 & 1200 & 9.5006 & 9.5643 & -0.3732 \\
\hline \multirow{5}{*}{$b 000$} & -20 & 12000 & 12.1557 & -10.3703 & -20.5031 \\
\cline { 2 - 6 } & -10 & 13500 & 5.5721 & -5.0289 & -10.2570 \\
\cline { 2 - 6 } & 10 & 16500 & -4.7953 & 4.76233 & 10.2661 \\
\cline { 2 - 6 } & 20 & 18000 & -8.9816 & 9.29300 & 20.5408 \\
\hline \multirow{5}{*}{$b=1.5$} & -20 & 1.2 & -0.0709 & 0.0687 & 0.1435 \\
\cline { 2 - 6 } & -10 & 1.35 & -0.0358 & 0.0343 & 0.0716 \\
\cline { 2 - 6 } & 10 & 1.65 & 0.0367 & -0.0343 & -0.0718 \\
\cline { 2 - 6 } & 20 & 1.8 & 0.0725 & -0.0682 & -0.1437 \\
\hline
\end{tabular}


Table 3. Sensitivity table of the parameters on the optimal solution for Example 1

\begin{tabular}{|c|c|c|c|c|c|}
\hline \multirow{2}{*}{ Parameter } & \multirow{2}{*}{$\begin{array}{c}\text { Change } \\
{[\%]}\end{array}$} & \multirow{2}{*}{ Value } & \multicolumn{3}{|c|}{ Per cent change } \\
\hline & & & $T^{*}$ & $Q^{*}$ & $T P U^{*}$ \\
\hline \multirow{4}{*}{$x=45$} & -20 & 36 & 4.8253 & 4.8564 & 28.5960 \\
\hline & -10 & 40.5 & 2.3280 & 2.3420 & 14.2969 \\
\hline & 10 & 49.5 & -2.1744 & -2.1881 & -14.2951 \\
\hline & 20 & 54 & -4.2137 & -4.2387 & -28.5883 \\
\hline \multirow{4}{*}{$p=70$} & -20 & 56 & -0.0709 & 0.0687 & -48.7542 \\
\hline & -10 & 63 & -0.0358 & 0.0343 & -24.3599 \\
\hline & 10 & 77 & 0.0367 & -0.0343 & 24.3252 \\
\hline & 20 & 84 & 0.0725 & -0.0682 & 48.6163 \\
\hline \multirow{4}{*}{$c=30$} & -20 & 24 & -0.1735 & -0.1750 & -1.1082 \\
\hline & -10 & 27 & -0.0859 & -0.0872 & -0.5542 \\
\hline & 10 & 33 & 0.0876 & 0.08777 & 0.5540 \\
\hline & 20 & 36 & 0.1752 & 0.1761 & 1.1080 \\
\hline \multirow{4}{*}{$L=0.025$} & -20 & 0.0200 & 0.3154 & 0.3173 & 1.9947 \\
\hline & -10 & 0.0225 & 0.1577 & 0.1581 & 0.9972 \\
\hline & 10 & 0.0275 & -0.1560 & -0.1576 & -0.9975 \\
\hline & 20 & 0.0300 & -0.3120 & -0.3141 & -1.9947 \\
\hline \multirow{4}{*}{$d_{1}=0.2$} & -20 & 0.16 & -1.6437 & -1.6544 & -10.7216 \\
\hline & -10 & 0.18 & -1.1047 & -1.1123 & -7.1479 \\
\hline & 10 & 0.22 & 1.1439 & 1.1509 & 7.1481 \\
\hline & 20 & 0.24 & 1.7305 & 1.7411 & 10.7225 \\
\hline \multirow{4}{*}{$I_{e}=0.3$} & -20 & 0.24 & 0.3154 & 0.3173 & 1.9947 \\
\hline & -10 & 0.27 & 0.1577 & 0.1581 & 0.9972 \\
\hline & 10 & 0.33 & -0.1560 & -0.1576 & -0.9975 \\
\hline & $20 \%$ & 0.36 & -0.3120 & -0.3141 & -1.9948 \\
\hline \multirow{4}{*}{$s_{c}=1$} & -20 & 0.8 & 0.1168 & 0.1174 & 0.7387 \\
\hline & -10 & 0.9 & 0.0584 & 0.0587 & 0.3692 \\
\hline & 10 & 1.1 & -0.0575 & -0.0581 & -0.3695 \\
\hline & 20 & 1.2 & -0.1151 & -0.1163 & -0.7390 \\
\hline \multirow{4}{*}{$m=0.05$} & -20 & 0.04 & 0.3554 & -0.6918 & 0.3844 \\
\hline & -10 & 0.045 & 0.1793 & -0.3464 & 0.1931 \\
\hline & 10 & 0.055 & -0.1810 & 0.3474 & -0.1955 \\
\hline & 20 & 0.06 & -0.3646 & 0.6965 & -0.3931 \\
\hline \multirow{4}{*}{$\theta=0.1$} & -20 & 0.08 & 7.5555 & 7.3910 & 0.2718 \\
\hline & -10 & 0.09 & 4.8521 & 4.7475 & 0.1791 \\
\hline & 10 & 0.11 & -4.2488 & -4.1524 & -0.1714 \\
\hline & 20 & 0.12 & -6.1704 & -6.0428 & -0.2545 \\
\hline \multirow{4}{*}{$h=5$} & -20 & 4 & 6.0236 & 6.0629 & 0.3381 \\
\hline & -10 & 4.5 & 2.8880 & 2.8979 & 0.2219 \\
\hline & 10 & 5.5 & -2.6501 & -2.6662 & -0.2100 \\
\hline & 20 & 6 & -5.1000 & -5.1229 & -0.3111 \\
\hline
\end{tabular}


The following observations can be made from Table 3:

The optimal total profit per unit time $\left(T P U_{1}^{*}\right)$ increases with the increase in the values of $a, p, c, d_{1}$ and decreases with the increase in the values of $A, b, x, L, I_{e}, s_{c}, m, \theta$ and $h$. TPU $U_{1}^{*}$ is highly sensitive to $a, x, p$, and $d_{1}$. That is, if the values of these parameters increase then $T P U_{1}^{*}$ changes rapidly. On the other hand, $T P U_{1}^{*}$ is moderately sensitive to the parameters $A, c, L, I_{e}, s_{c}, m, \theta$, and $h$. It indicates that $T P U_{1}^{*}$ increases or decreases gradually when the values of these parameters increase. Again, $T P U_{1}^{*}$ is less sensitive to $b$ as it shows very little change in its values when $b$ increases.

The optimal ordering quantity $\left(Q^{*}\right)$ increases with the increase in the values of $A, a, c, d_{1}$, and $m$, but it decreases with the increase in the values of $b, x, p, L, I_{e}, s_{c}, \theta$, and $h . Q^{*}$ is highly sensitive to the parameters $A, a, x, \theta$, and $h$. On the other hand, it is moderately sensitive to $L, d_{1}, I_{e}$, and $m$. But $Q^{*}$ is less sensitive concerning the parameters $b, p, c$, and $s_{c}$.

The optimal cycle length $\left(T^{*}\right)$ increases with increasing the values of $A, b, p, c, d_{1}$ and decreases with the increase in the values of $a, x, L, I_{e}, s_{c}, m, \theta$, and $h . T^{*}$ is highly sensitive to the parameters $A, a, x, \theta$, and $h$, moderately sensitive to $L, d_{1}, I_{e}$, and $m$; less sensitive to $b, p, c$ and $s_{c}$.

\section{Managerial insight}

To increase the total profit of the system based on the numerical examples and analysing the impact of inventory parameters, the following managerial implications may be made.

- As the total average profit in case of full advance payment is more than that of partial advance payment, it is recommended for the buyer to prefer a full advance payment policy.

- When the unit purchase cost decreases, it is observed that the total average profit increases significantly. Thus, it is recommended for the decision-maker to negotiate with the supplier or vendor to reduce the unit purchase cost of the item so that the buyer procures more items and increases the profit.

- When the discount rate increases, the total average profit also increases which is apparent. Moreover, in this case, the retailer has an incentive to purchase more quantity. Thus, the inventory manager should purchase goods from a supplier who offers a greater discount rate. 
- As the loan interest decreases, the total profit increases. This scenario is expected. Thus, the manager should approach to third party or supplier who offers a loan with a lower interest rate.

- Increase in the initial demand rate increases the total average profit and ordering quantity. Thus, in this case, the buyer ought to order more quantities to increase the total profit.

- Increase in the fraction of imperfect items in the lot decreases the total profit which is apparent. Thus, the manager should take appropriate strategy so that the received lot contains less number of imperfect items.

\section{Conclusion}

This paper presents an inventory model for imperfect quality items under deteriorating conditions. The screening rate is assumed to be greater than the demand rate so that customers' demand can be met up out of the perfect items during screening. The model is developed under an advance payment policy and cash discount facility due to advance payment. The total profit function formulated in each case is pseudo concave. Moreover, the obtained optimal solution in each case is unique global maximum. It is observed that the total profit under a full advance payment scheme is more than that in the case of partial advance payment. Thus, it is recommended to the retailer/buyer to go with a full advance payment scheme. Further, a sensitivity analysis is carried out to study the effects on the total profit due to the changes in the different system parameters. The results of the sensitivity analysis show that the demand parameter $a$, the unit purchase cost $x$ and discount rate $d_{1}$ are significant parameters concerning total profit. That is, elevating customers' demand by executing proper marketing strategies and reducing unit purchase costs by negotiating with the supplier to raise the total profit of the system. Also, a higher discount offering supplier is first to be preferred. Moreover, corrective measures in the direction of procuring good quality items need to be taken as an increase in imperfect items in the lot reduces the total profit of the system.

In this present study, shortages were not allowed to occur, which is a limitation of this model. Thus, this gives a further scope to extend this model under the assumption of the occurrence of shortages. In this model, for smooth supply of customers' demand, it is assumed that inventory of good items should be enough to meet the demand during screening, which is another limitation of this model. One may extend this model by relaxing this assumption and may include the concept of safety stock. Another possible extension is to consider the lead time as fuzzy or stochastic or interval number. As the deterioration negatively affects the total profit, one may also study the effect of preservation technology investment on the profit of the system. 


\section{References}

[1] Agrawal S., Gupta R., BANERJEe S., EOQ model under discounted partial advance partial trade credit policy with price-dependent demand, [In:] N.H. Shah, M. Mittal (Eds.), Optimization and Inventory Management, Springer, Singapore 2020, 219-237.

[2] Alfares H.K., Ghaithan A.M., Inventory and pricing model with price-dependent demand, timevarying holding cost, and quantity discounts, Comp. Ind. Eng., 2016, 94, 170-177.

[3] BALKHI Z.T., An optimal solution of a general lot size inventory model with deteriorated and imperfect products, taking into account inflation and time value of money, Int. J. Sys. Sci., 2004, 35 (2), 87-96.

[4] Ben-Daya M., Hariga M., Economic lot scheduling problem with imperfect production processes, J. Oper. Res. Soc., 2000, 51 (7), 875-881.

[5] Bhunia A., SHAIKH A., A deterministic inventory model for deteriorating items with selling price dependent demand and three-parameter Weibull distributed deterioration, Int. J. Ind. Eng. Comp., 2014, 5 (3), 497-510.

[6] CAMBINI A., MARTEIn L., Generalized convexity and optimization: Theory and applications, Vol. 616, Springer, Berlin 2008.

[7] CÁRDENAS-BARRÓN L.E., Observation on "Economic production quantity model for items with imperfect quality” [Int. J. Prod. Econ., 64 (2000) 59-64], Int. J. Prod. Econ., 2000, 67 (2), 201-201.

[8] ChaUdhari U., SHAH N.H., JANI M.Y., Inventory modelling of deteriorating item and preservation technology with advance payment scheme under quadratic demand, [In:] N.H. Shah, M. Mittal (Eds.), Optimization and Inventory Management, Springer, Singapore 2020, 69-79.

[9] CHENG T.C.E., An economic order quantity model with demand-dependent unit production cost and imperfect production processes, IIE Trans., 1991, 23 (1), 23-28.

[10] Das S.C., Manna A.K., RAhman M.S., Shaikh A.A., Bhunia A.K., An inventory model for non-instantaneous deteriorating items with preservation technology and multiple credit periods-based trade credit financing via particle swarm optimization, Soft Comp., 2021, 25 (7), 5365-5384.

[11] Goyal S.K., CÁRDENAS-BARRÓN L.E., Note on: economic production quantity model for items with imperfect quality. A practical approach, Int. J. Prod. Econ., 2002, 77 (1), 8-87.

[12] GuPTA R., BANERJEe S., AgRAWAL S., Retailer's optimal payment decisions for price-dependent demand under partial advance payment and trade credit in different scenarios, Int. J. Sci. Res. Math. Stat. Sci., 2018, 5 (4), 44-53.

[13] GUPTA R.K., BhUNIA A.K., GoYAl S.K., An application of genetic algorithm in solving an inventory model with advance payment and interval valued inventory costs, Math. Comp. Model., 2009, 49 (5-6), 893-905.

[14] HarRis F.W., Operations and cost, factory management, Prod. Oper. Manage., 1915, 5, 1-6.

[15] He Y., HuAng H., Optimizing inventory and pricing policy for seasonal deteriorating products with preservation technology investment, J. Ind. Eng., 2013, 2013, 1-7.

[16] Hou K.L., LiN L.C., Optimal production run length and capital investment in quality improvement with an imperfect production process, Int. J. Sys. Sci., 2004, 35 (2), 133-137.

[17] JAGGi C.K., CÁRDENAS-BARRÓn L.E., TIWARI S., SHAFI A., Two-warehouse inventory model for deteriorating items with imperfect quality under the conditions of permissible delay in payments, Sci. Iranica, 2017, 24 (1), 390-412.

[18] JAGGI C.K., TIWARI S., GOEL S.K., Credit financing in economic ordering policies for non-instantaneous deteriorating items with price dependent demand and two storage facilities, Ann. Oper. Res., 2017, 248 (1-2), 253-280.

[19] KARLIN S., One stage inventory models with uncertainty, [In:] S. Karlin, H. Scarf(Eds.), Studies in the Mathematical Theory of Inventory and Production, Stanford University Press, Stanford, CA, 1958, 109-134. 
[20] Khan M.A.A., Ahmed S., Babu M.S., Sultana N., Optimal lot-size decision for deteriorating items with price-sensitive demand, linearly time-dependent holding cost under all-units discount environment, Int. J. Sys. Sci. Oper. Log., 2020, 9, 1-14.

[21] Khan M., JABER M.Y., GUiffrida A.L., Zolfaghari S., A review of the extensions of a modified EOQ model for imperfect quality items, Int. J. Prod. Econ., 2011, 132 (1), 1-12.

[22] Khan M.A.A., Shaikh A.A., Panda G.C., Bhunia A.K., Konstantaras I., Non-instantaneous deterioration effect in ordering decisions for a two-warehouse inventory system under advance payment and backlogging, Ann. Oper. Res., 2020, 289, 243-275.

[23] Khan M.A.A., Shaikh A.A., PANDa G.C., Konstantaras I., Two-warehouse inventory model for deteriorating items with partial backlogging and advance payment scheme, RAIRO Oper. Res., 2019, 53 (5), 1691-1708.

[24] Khan M.A.A., Shaikh A.A., Panda G.C., Konstantaras I., CÁrdenas-Barrón L.E., The effect of advance payment with discount facility on supply decisions of deteriorating products whose demand is both price and stock dependent, Int. Trans. Oper. Res., 2020, 27 (3), 1343-1367.

[25] KhAn M.A.A., SHAikH A.A., CÁRDENAS-BARRÓN L.E., An inventory model under linked-to-order hybrid partial advance payment, partial credit policy, all-units discount and partial backlogging with capacity constraint, Omega, 2021, 103, 102418.

[26] Khan M.A.A., Shaikh A.A., Konstantaras I., Bhunia A.K., CÁrdenas-Barrón L.E., Inventory models for perishable items with advanced payment, linearly time-dependent holding cost and demand dependent on advertisement and selling price, Int. J. Prod. Econ., 2020, 230, 107804.

[27] Khanna A., Kishore A., SarKar B., JaGgi C.K., Supply chain with customer-based two-level credit policies under an imperfect quality environment, Mathematics, 2018, 6 (12), 299-333.

[28] Krommyda I.P., SKouri K., Lagodimos A.G., A unified EOQ model with financial constraints and market tolerance, Appl. Math. Model, 2019, 65, 89-105.

[29] Kumar A., KAANODIYA K.K., PACHAURI R.R., Retailer's optimal ordering policies with two stage credit policies and imperfect quality, Int. Bus. Manage., 2011, 3 (1), 77-81.

[30] Lashgari M., Taleizadeh A.A., Ahmadi A., Partial up-stream advanced payment and partial downstream delayed payment in a three-level supply chain, Ann. Oper. Res., 2016, 238 (1-2), 329-354.

[31] Li R., Liu Y., Teng J.T., Tsao Y.C., Optimal pricing, lot-sizing and backordering decisions when a seller demands an advance-cash-credit payment scheme, Eur. J. Oper. Res., 2019, 278 (1), 283-295.

[32] Mainami R., GhalehkHondabi I., Ahmadi E., Pricing and inventory planning for non-instantaneous deteriorating products with greening investment. A case study in beef industry, J. Cleaner Prod., 2021, 295, 126368.

[33] Maiti A.K., Maiti M.K., Maiti M., Inventory model with stochastic lead-time and price dependent demand incorporating advance payment, Appl. Math. Model., 2009, 33 (5), 2433-2443.

[34] MANDAL P., GIRI B.C., A two-warehouse integrated inventory model with imperfect production process under stock-dependent demand and quantity discount offer, Int. J. Sys. Sci. Oper. Log., 2019, 6 (1), 15-26.

[35] Manna A.K., Das B., Dey J.K., Mondal S.K., Effect of inspection errors on imperfect production inventory model with warranty and price discount dependent demand rate, RAIRO Oper. Res., 2020, 54, 1189-1213.

[36] MAShUd A.H.M., WeE H.M., SARKAR B., Li Y.H.C., A sustainable inventory system with the advanced payment policy and trade-credit strategy for a two-warehouse inventory system, Kybernetes, 2020, 50 (5), 1321-1348.

[37] Mishra U., Tijerina-Aguilera J., Tiwari S., CÁRdenas-BARRón L.E., Retailer's joint ordering, pricing, and preservation technology investment policies for a deteriorating item under permissible delay in payments, Math. Probl. Eng., 2018, 2018, 1-14. 
[38] Mondal B., Bhunia A.K., Maiti M., Inventory models for defective items incorporating marketing decisions with variable production cost, Appl. Math. Model., 2009, 33 (6), 2845-2852.

[39] Moussawi-Haidar L., Salameh M., NASR W., Effect of deterioration on the instantaneous replenishment model with imperfect quality items, Appl. Math. Model., 2014, 38 (24), 5956-5966.

[40] OuYANG L.Y., Chang C.T., Shum P., The EOQ with defective items and partially permissible delay in payments linked to order quantity derived algebraically, Central Eur. J. Oper. Res., 2012, 20 (1), 141-160.

[41] PAPAChristos S., KonstantaRAS I., Economic ordering quantity models for items with imperfect quality, Int. J. Prod. Econ., 2006, 100 (1), 148-154.

[42] PorTeus E.L., Optimal lot sizing, process quality improvement and setup cost reduction, Oper. Res., 1986, 34 (1), 137-144.

[43] Rahman M.S., DuARY A., Shaikh A.A., BhUnia A.K., An application of parametric approach for interval differential equation in inventory model for deteriorating items with selling-price-dependent demand, Neural Comp. Appl., 2020, 32, 14069-14085.

[44] Rahman M.S., Khan M.A.A., Halim M.A., Nofal T.A., Shaikh A.A., Mahmoud E.E., Hybrid price and stock dependent inventory model for perishable goods with advance payment related discount facilities under preservation technology, Alexandria Eng. J., 2021, 60 (3), 3455-3465.

[45] Rosenblatt M., LeE H., Economic production cycles with imperfect production processes, IIE. Trans., 1986, 18 (1), 48-55.

[46] SAHA S., SEN N., A study on inventory model with negative exponential demand and probabilistic deterioration under backlogging, Unc. Supp. Chain Manage., 2017, 5 (2), 77-88.

[47] SaHa S., SEN N., An inventory model for deteriorating items with time and price dependent demand and shortages under the effect of inflation, Int. J. Math. Oper. Res., 2019, 14 (3), 377-388.

[48] SAlameH M.K., Jaber M.Y., Economic production quantity model for items with imperfect quality, Int. J. Prod. Econ., 2000, 64 (1-3), 59-64.

[49] SAna S.S., Price-sensitive demand for perishable items - an EOQ model, Appl. Math. Comp., 2011, 217 (13), 6248-6259.

[50] SARKAR B., An EOQ model with delay in payments and stock dependent demand in the presence of imperfect production, Appl. Math. Comp., 2012, 218 (17), 8295-8308.

[51] SHAIKH A., Mishra P., Optimal policies for price sensitive quadratic demand with preservation technology investment under inflationary environment, J. Adv. Manuf. Sys., 2019, 18 ( 2), 325-337.

[52] Shaikh A.A., CARDEnas-BARRon L.E., Tiwari S., Economic production quantity (EPQ) inventory model for a deteriorating item with a two-level trade credit policy and allowable shortages, [In:] N.H. Shah, M. Mittal (Eds.), Optimization and Inventory Management, Springer, Singapore 2020, 1-19.

[53] Shaikh A.A., Das S.C., Bhunia A.K., PANDA G.C., KhAn M.A.A., A two-warehouse EOQ model with interval-valued inventory cost and advance payment for deteriorating item under particle swarm optimization, Soft Comp., 2019, 23 (24), 13531-13546.

[54] Shaikh A.A., Mashud A.H.M., UdDIN M.S., Khan M.A.A., Non-instantaneous deterioration inventory model with price and stock dependent demand for fully backlogged shortages under inflation, Int. J. Bus. Forecast. Market. Int., 2017, 3 (2), 152-164.

[55] Shaikh A.A., Panda G.C., Khan M.A.A., Mashud A.H.M., Biswas A., An inventory model for deteriorating items with preservation facility of ramp type demand and trade credit, Int. J. Math. Oper. Res., 2020, 17 (4), 514-551.

[56] Singh T., Mishra P.J., PatTANAyAK H., An EOQ inventory model for deteriorating items with timedependent deterioration rate, ramp-type demand rate and shortages, Int. J. Math. Oper. Res., 2018, 12 (4), 423-437.

[57] SRIDEVI G., NiRUPAMA DEVI K., SRINIVASA RAO K., Inventory model for deteriorating items with Weibull rate of replenishment and selling price dependent demand, Int. J. Oper. Res., 2010, 9 (3), 329-349. 
[58] Sulak H., Eroglu A., Bayhan M., Avci M.A., An economic order quantity model for defective items under permissible delay in payments and shortage, Int. J. Acad. Res. Bus. Soc. Sci., 2015, 5 (1), 302-316.

[59] TAleIZADEH A.A., An economic order quantity model for deteriorating item in a purchasing system with multiple prepayments, App. Math. Model., 2014, 38 (23), 5357-5366.

[60] Taleizadeh A.A., Pentico D.W., Jabalameli M.S., Aryanezhad M., An economic order quantity model with multiple partial prepayments and partial backordering, Math. Comp. Model., 2013, 57 (3-4), 311-323.

[61] Tavakoli S., Taleizadeh A.A., An EOQ model for decaying items with full advance payment and conditional discount, Ann. Oper. Res., 2017, 259 (1-22), 415-436.

[62] Thangam A., Optimal price discounting and lot-sizing policies for perishable items in a supply chain under advance payment scheme and two-echelon trade credits, Int. J. Prod. Econ., 2012, 139 (2), 459-472.

[63] Tiwari S., CÁRdEnAS-BARRón L.E., GoH M., SHAikH A.A., Joint pricing and inventory model for deteriorating items with expiration dates and partial backlogging under two-level partial trade credits in supply chain, Int. J. Prod. Econ., 2018, 200, 16-36.

[64] Xu C., LiU X., Wu C., YuAn B., Optimal inventory control strategies for deteriorating items with a general time-varying demand under carbon emission regulations, Energies, 2020, 13 (4), 1-20.

[65] ZHANG A.X., Optimal advance payment scheme involving fixed per-payment costs, Omega, 1996, 24 (5), 577-582.

[66] Zhang Q., TSAO Y.C., CHEN T.H., Economic order quantity under advance payment, App. Math. Model., 2014, 38 (24), 5910-5921.

[67] Zhang Q., Zhang D., Tsao Y.C., Luo J., Optimal ordering policy in a two-stage supply chain with advance payment for stable supply capacity, Int. J. Prod. Econ., 2016, 177, 34-43.

[68] ZIA N.P., TALEIZADEH A.A., A lot-sizing model with backordering under hybrid linked-to-order multiple advance payments and delayed payment, Transp. Res., Part E. Log. Transp. Rev., 2015, 82, 19-37. 